\title{
A scale for monitoring students' attitudes to learning mathematics with technology
}

\author{
Robyn Pierce $^{\mathrm{a}, *}$, Kaye Stacey ${ }^{\mathrm{b}}$, Anastasios Barkatsas ${ }^{\mathrm{b}}$ \\ ${ }^{\text {a }}$ University of Ballarat, P.O. Box 663, Ballarat, Victoria 3353, Australia \\ ${ }^{\mathrm{b}}$ University of Melbourne, Australia
}

\section{Abstract}

10 The Mathematics and Technology Attitudes Scale (MTAS) is a simple scale for middle secondary years 11 students that monitors five affective variables relevant to learning mathematics with technology. The sub12 scales measure mathematics confidence, confidence with technology, attitude to learning mathematics with 13 technology and two aspects of engagement in learning mathematics. The paper presents a model of how 14 technology use can enhance mathematics achievement, a review of other instruments and a psychometric 15 analysis of the MTAS. It also reports the responses of 350 students from 6 schools to demonstrate the 16 power of the MTAS to provide useful insights for teachers and researchers. 'Attitude to learning mathemat17 ics with technology' had a wider range of scores than other variables studied. For boys, this attitude is cor18 related only with confidence in using technology, but for girls the only relationship found was a negative 19 correlation with mathematics confidence. These differences need to be taken into account when planning 20 instruction.

21 (C) 2005 Published by Elsevier Ltd.

22 Keywords: Applications in subject areas; Evaluation methodologies; Gender studies; Pedagogical issues; Secondary 23 education

\footnotetext{
* Corresponding author. Tel.: +61 353 279283; fax: +61 353279289.

E mail address: r.pierce@ballarat.edu.au (R. Pierce).
} 


\section{1. Introduction}

\section{3}

26 Technology offers enticing possibilities for new approaches to teaching and hence for learning across the curriculum. The research and professional literature suggests that the new approaches may enhance learning through cognitive, metacognitive and affective channels. The cognitive and metacognitive channels for improving learning by using technology are clearly strong and important to study. This paper provides a tool, the Mathematics and Technology Attitudes Scale (MTAS), to examine the role of the affective channel, which is also important in improving learning, and it reports some results from the use of MTAS in six schools.

33 For learning and doing mathematics, technology in the form of 'mathematics analysis tools' (such as certain computer software, calculators, graphics calculators, computer algebra systems, spreadsheets, statistics programs) can assist students' problem solving, support exploration of mathematical concepts, provide dynamically linked representations of ideas and can encourage general metacognitive abilities such as planning and checking. In addition, information technology in the form of 'real world interfaces' such as digital cameras, video cameras and data loggers can bring to life in the classroom those outside situations to which mathematics is applied (see, for example, Oldknow, 2003). With substantial investment in providing information technology to assist in teaching and learning mathematics, it is important to monitor students' reactions and decide how best to use both forms of technology, the mathematics analysis tools and the real world interfaces.

43 Reports of almost any major teaching innovation of the last 25 years include data on students' attitudes to the innovation as well as their mathematical achievement. McLeod (1992), who provides a careful analysis of previous research on affect in mathematics education, is adamant that affective issues play a central role in mathematics learning and that 'mathematics education research can be strengthened if researchers integrate affective issues into studies of cognition and instruction' (p. 575). The literature published since 1992 also affirms that affective factors and beliefs impact on student learning: in general positive attitudes and beliefs and intrinsic motivation are reflected in increased effort in learning and greater persistence. Ruffell, Mason, and Allen (1998) are concerned that attitudes may not be sufficiently well defined conceptually or sufficiently stable to be reliable but 'influenced by social and emotional context and personal construction of these' (p. 15). We would agree with Ruffell et al. that attitudes can 'flip' from negative to positive and in particular that 'good teaching' can have such an effect, but we disagree that this means that monitoring attitude will not prove fruitful for mathematics education research. Since attitudes can be affected by recent experience, a series of experiences promoting positive or negative attitude can indeed contribute to the development of more persistent attitudes and even beliefs which are deeply held and strongly influence future behaviour. Attitudes are commonly distinguished from beliefs in that attitudes are moderate in duration, intensity and stability and have an emotional content, while beliefs become stable and are not easily changed (Mayes, 1998; McLeod, 1992; Pajares, 1992). In this paper, we do not make a strict distinction between attitudes and beliefs, but use the terms 'attitude' and 'affective' to encompass both feelings and opinions about doing and learning mathematics.

\subsection{The hypothesized model}

This paper reports the development of a scale to monitor affective changes which result from technology use and which are likely to have an impact on improving learning. Fig. 1 outlines a 


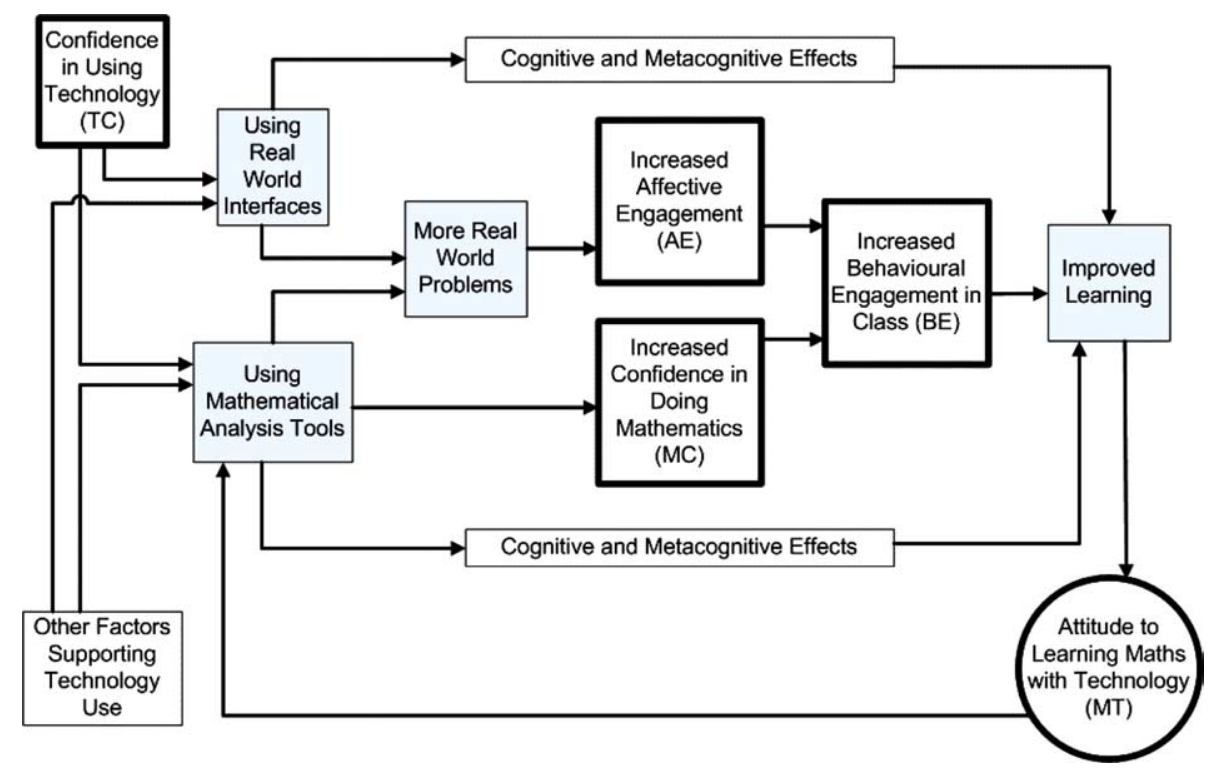

Fig. 1. Illustration of hypothesized affective channel for technology use to improve mathematics learning. (Variables measured in MTAS in heavily outlined boxes: MC, TC, AE, BE, MT).

hypothesized model. The main row of boxes across the centre of Fig. 1 shows that we hypothesize that information technology in the classroom can enable more real world problem solving. Both forms of technology, the mathematics analysis tools and the real world interfaces, contribute. More real problem solving, making mathematics more relevant to students' lives and more interesting, is in turn hypothesized to lead to increased 'affective engagement' (defined below). Use of mathematical analysis tools is, in addition, hypothesized to lead to increased confidence in doing mathematics because these can take some of the computational burden from students. These effects combine to improve students' behavioural engagement (defined below) during lessons and hence improve learning. Confidence in using technology (extreme left side box) is seen as predisposing students to full participation in lessons using technology, along with a number of unspecified factors (e.g., having suitable equipment and a teacher willing and able to use it). Similarly, both forms of technology have cognitive and metacognitive effects (elongated top and bottom boxes) which will impact on learning but are not of concern here. On the bottom right hand side, a positive attitude to using technology to learn mathematics is shown as an outcome of improved learning. However, a favourable attitude also provides a feedback loop, making further effective use of technology for learning likely. Evidence for this is provided from the multiple case studies reported by Pierce and Stacey (2004). This paper aims to provide a simple instrument which can be used to explore whether these links are evident in practice, although there is no attempt in this paper to fully test the model.

85 This study is linked to the RITEMATHS project (HREF1), which is conducting a series of curriculum design experiments for middle secondary school teaching of mathematics. Based on the broad experience of the teaching and research team and relevant literature, we plan to make strategic use of technology to facilitate the use of real world problems in mathematics classes, aiming 


\section{2. The need for another scale}

113 Attitudes have been studied in various ways, with data collected from individual interviews, fo-

to increase students' engagement and confidence and thereby increase achievement as shown in Fig. 1. Consequently, we wish to track changes in the attitudes and engagement of students in their learning of mathematics, in response to the altered learning environment and to consider how best this use of technology can be implemented. The five heavily outlined boxes in Fig. 1 show the constructs measured by the MTAS, all of which are relevant to our proposed RITEMATHS curriculum changes.

95 In a curriculum design experiment like the RITEMATHS project, it is important to monitor student attitudes throughout the project. The malleable nature of attitudes means that it may be possible to create repeated episodes engendering positive attitudes and so, in time, contribute to these students establishing positive stable beliefs and behaviours for their mathematics learning. The need to assess students' attitudinal response before and after each teaching experiment prompts the requirement for a minimally intrusive method of collecting data. For this reason a simple questionnaire approach was chosen as the primary source of data. This will, of course be 'self-report' data and any claims of changes over time will need to be confirmed by classroom observation, and teacher and student interviews.

For our study we want subscales which allow us to monitor the five variables highlighted in Fig. 1: mathematics confidence (MC), affective engagement (AE), behavioural engagement (BE), confidence in using technology (TC) and attitude to the use of technology to learn mathematics (MT). The rest of this paper discusses some of the available scales, our choices of items, and the psychometric analysis of the resulting MTAS, which is given in Appendix A. We then demonstrate the power of MTAS to provide useful insights for teachers, by reporting on differences between schools and between genders. We will begin by considering relevant literature and establishing the need for a new scale for ongoing monitoring of students. cus groups, diaries, observation and questionnaires. Since the research of Fennema and Sherman in the 1970s, questionnaires have become standard tools for assessing student attitudes, especially when attitudes alone are not the focus of the study but rather viewed as one factor to be monitored when assessing the likely success of a curriculum or teaching innovation. The literature does not support one approach over another. In every case the act of asking questions will prompt thoughts in the mind of some students which they may not have otherwise had and they will feel obliged to answer. Asking students to pause and reflect briefly to respond to a questionnaire may therefore provide data which would not be obvious through observation and would take too much time to collect by interviewing every student.

123 We need an instrument that is suitable for students as young as fourteen, with widely varying scholastic abilities. Since the project will monitor curriculum innovations, the instrument will need to be administered regularly without taking too much class time. Some well known instruments are too long and complex for our purpose. For example, the classic Fennema and Sherman (1976) scale, which measures some constructs of interest to us, has 108 items and according to Tapia and Marsh (2004) one needed to allow students up to $45 \mathrm{~min}$. Scales also become dated. Shades of meaning of words change and, while older scales provide most help- 
ful models, new items need to be constructed which will be immediately understood by the current student cohort. Other recent research in our Australian context provides resources on which a suitable scale may be built. For example, Galbraith and Haines (1998) provide a contemporary resource but their subjects were tertiary students and their focus, related to particular courses, meant that items were not immediately transferable to our study. Similarly, Fogarty, Cretchley, Harman, Ellerton, and Konki (2001) validated a questionnaire to measure tertiary students' mathematics confidence, computer confidence and attitudes towards the use of technology for learning mathematics. Their scale, focused on just these three constructs, has 37 items including a number of long statements, making it unsuitable for direct transfer to our setting. Chapman (2003), on the other hand, produced a validated scale for use with primary aged students. Her 'How I feel About Maths' scale focuses mainly on the construct we will describe below as 'affective engagement'. The items in this scale provide exemplars of brief, simply worded statements which each address one idea but the scale does not cover the breath of attitudes we consider important for our study. Vale and Leder (2004) report a study of the relationship between gender and attitudes to using computers for learning mathematics using a questionnaire as one source of data. While their scale is targeted at the same age range as our study (early/middle secondary years), and the issue of gender may emerge as an important variable, we want to look more broadly. The Vale and Leder scale had 11 items for 'attitude to computer-based mathematics' and only one item for each of four other variables.

150 While acknowledging the advantage of building on previous research without modification, none of the available scales was deemed suitable for repeated monitoring of students' attitudes in a diversity of middle secondary years classes. However the scale we have constructed has many ideas and some items in common with other published scales. We have minimised the number of items and constructed short statements. In addition, we have avoided the use of negatively worded items, for two reasons. First, we want students to be able to complete the questionnaire quickly and accurately and negative items often cause some hesitation or incorrect responses due to the logic of double negatives etc. Second, since a student may complete this questionnaire many times over three years, we do not want to seed negative thinking. While negatively worded items are commonly included in order to address possible acquiescence in response to items this was not considered to be a major problem with our participants, who operate within a school culture where they feel their opinions are valued and criticism (implied or direct) of authorities is common.

\section{3. Key concepts considered}

164 Defining the composition of attitudes is not simple. In the literature referenced in this paper 165 there is general agreement that confidence and engagement are important but certainly not precise agreement as to their measurable features. Students' vocabulary and behaviour indicating confidence and engagement will be dependent on local culture and context, age and stage. These factors need to be taken in to consideration in wording the statements to which we ask students to respond. The section which follows includes the items we constructed, the meaning we have assigned to each construct and where that fits in relation to definitions used in other recent studies. 


\subsection{Mathematics confidence}

172 Vale and Leder (2004) view students' attitudes to mathematics as being defined by the students' perceptions of their achievement (self-efficacy) and their aspiration to achieve in the disciplines. Galbraith and Haines (1998) see mathematics confidence as evidenced by students "who believe they obtain value for effort, do not worry about learning hard topics, expect to get good results, and feel good about mathematics as a subject' (p. 278).

177 We have restricted our meaning of the term 'mathematics confidence' to a student's perception of their ability to attain good results and their assurance that they can handle difficulties in mathematics. The students' views are canvassed directly through five brief items shown in Table 1 . The item numbers include the letter $p$ (for preliminary) to indicate it is the numbering of items in the preliminary questionnaire, rather than the final MTAS, which is given in Appendix A. Since we wish to monitor change over time rather than take a single snap shot of student attitudes, we have framed items that seek their immediate reactions rather than asking students either to reflect on the past or consider their aspirations for the future. We have decided that whether or not students 'feel good about mathematics' (as in Galbraith and Haines' construct above) is sufficiently important to be separated from confidence and is considered under 'affective engagement'.

\section{7}

\subsection{Confidence with technology}

188 In this construct, Vale and Leder (2004) follow Forgasz (1995) in viewing students' attitudes to technology (in their case computers) as being defined by the students' perceptions of their achievement (self-efficacy) and their aspiration to achieve in these disciplines. This parallels the components of their construct of mathematics confidence. Galbraith and Haines (1998) take a different view, seeing technology confidence (again in their case this is computer confidence) as evidenced by students who ffeel self-assured in operating computers, believe they can master computer procedures required of them, are more sure of their answers when supported by a computer, and in cases of mistakes in computer work are confident of resolving the problem themselves' (p. 278). The meaning we have assigned to this construct closely matches that of Galbraith and Haines and differs from Vale and Leder. Table 2 lists the items we chose. Within the time of this project it is anticipated that many of the students involved will use a variety of technology in their mathematics classes. For this reason we included item $2 p$ which canvasses their confidence to use a broad range of commonly available technology. This also pointed to the construct of confidence with technology relating to life outside as well as inside the classroom.

Table 1

Items in preliminary questionnaire assessing mathematics confidence (MC)

\begin{tabular}{ll}
\hline Item number & Statement for response (given five point scale) \\
\hline $5 \mathrm{p}$ & I have a mathematical mind \\
$11 \mathrm{p}$ & I can get good results in mathematics \\
$12 \mathrm{p}$ & I know I can handle difficulties in mathematics \\
$16 \mathrm{p}$ & I am confident with mathematics \\
$18 \mathrm{p}$ & I have less trouble learning mathematics than other subjects \\
\hline
\end{tabular}


Table 2

Items in preliminary questionnaire assessing confidence with technology (TC)

\begin{tabular}{ll}
\hline Item number & Statement for response (given five point scale) \\
\hline $1 \mathrm{p}$ & I am good at using computers \\
$2 \mathrm{p}$ & I am good at using things like VCRs, DVDs, MP3s and mobile phones \\
$3 \mathrm{p}$ & I can fix a lot of computer problems \\
$4 \mathrm{p}$ & I would be more confident of my school work with a computer to help me \\
$19 \mathrm{p}$ & I can master any computer programs needed for school \\
\hline
\end{tabular}

\section{3.3. Attitude towards use of technology for learning mathematics}

204 Vale and Leder (2004) measured 'attitude to computer-based mathematics' with 11 items, defin205 ing it as 'the degree to which students perceive that the use of computers in mathematics provides relevance for mathematics, aids their learning of mathematics and contributes to their achievement in mathematics' (p. 291). Galbraith and Haines (1998) define a similar construct which they call 'computer and mathematics interaction'. They claim that in their context 'Students indicating high computer and mathematics interaction believe that computers enhance mathematical learning by the provision of many examples, find note-making helpful to augment screen based information, undertake a review soon after each computer session, and find computers helpful in linking algebraic and geometric ideas' (p. 279).

213 In this case, our construct is closer to that of Vale and Leder (2004) than Galbraith and Haines 214 (1998). We have focused broadly on interest and assistance to learning without expecting the more sophisticated and specific reflections which Galbraith and Haines sought from tertiary students. In this quick survey we do not expect 14 and 15-year-old students to analyse the ways in which technology contributes to their learning of mathematics. If and when this level of detail may be helpful, we will use interviews which allow for clarification of both questions and the students' responses. While the simple items we constructed, shown in Table 3, use the term 'graphics calculator' other versions of this questionnaire replace this term with 'computer' or 'computer algebra system', depending on the mathematical analysis tools used by the specific group of students surveyed. Only items related to this construct are varied in this way.

\section{3.4. Affective and behavioural engagement}

224 Next we consider the two aspects of engagement. Fredricks, Blumenfeld, and Paris (2004) pro225 vide a comprehensive overview of literature relating to school engagement in general. They see

Table 3

Items in preliminary questionnaire assessing attitude towards use of technology for learning mathematics (MT)

\begin{tabular}{ll}
\hline Item number & Statement for response (given five point scale) \\
\hline $8 \mathrm{p}$ & I like using graphics calculators for mathematics \\
$9 \mathrm{p}$ & I learn more when I use graphics calculators in mathematics \\
$14 \mathrm{p}$ & Using graphics calculators in mathematics is worth the extra effort \\
$15 \mathrm{p}$ & Mathematics is more interesting when using graphics calculators \\
$20 \mathrm{p}$ & Graphics calculators help me learn mathematics better \\
\hline
\end{tabular}

Graphics calculator version; replace with computer or other technology as appropriate. 
engagement as multifaceted with three components: behavioural engagement (positive conduct at school, involvement in learning and academic tasks, and participation in school-related activities), emotional engagement (affective reaction to school and classroom activities including boredom, happiness, and feelings of belonging) and cognitive engagement (psychological investment in learning or cognition and strategic learning). In our context (the learning of subject matter), we are concerned only with that part of school engagement which lies within the cognitive arena. Within this arena, we have decided to examine how students feel about the subject (which we call affective engagement, $\mathrm{AE}$ ) and how they behave in learning the subject (which we call behavioural engagement, BE).

35 Vale and Leder (2004) refer to a concept similar to affective engagement as 'girls/boys pleasure and computers' but in their study data on this was collected from classroom observations rather than by questionnaire. Chapman (2003) constructed a scale to specifically measure affective engagement. She did this by having students' respond on a five-point scale to items such as "Mathematics is boring" and "I like mathematics". The items we see as assessing affective engagement are listed in Table 4. Like Chapman (2003) we have also chosen to construct simple items but allow for the fact that middle secondary years students have years of experience of learning mathematics and, based on this experience, have started to develop views about their learning.

243 Items for our scale of behavioural engagement (see Table 5) examine what students do to learn in class. Galbraith and Haines (1998) discuss a related concept of 'mathematics engagement'. "Students who score highly on this scale [mathematical engagement] prefer to work through examples rather than learn given material, like to test understanding through exercises and problems, try to link new knowledge to existing knowledge, like to elaborate material with notes, and review their work regularly" (p. 280). We chose instead to focus on learning behaviour rather than on learning strategies, although the two concepts are related. This was in order to keep the con-

Table 4

Items in preliminary questionnaire assessing affective engagement (AE)

\begin{tabular}{ll}
\hline Item number & Statement for response (given five point scale) \\
\hline $6 \mathrm{p}$ & I am interested to learn new things in mathematics \\
$7 \mathrm{p}$ & In mathematics you get rewards for your effort \\
$10 \mathrm{p}$ & Learning mathematics is enjoyable \\
$13 \mathrm{p}$ & Mathematics is boring \\
$17 \mathrm{p}$ & I get a sense of satisfaction when I solve mathematics problems \\
\hline
\end{tabular}

Table 5

Items in preliminary questionnaire assessing behavioural engagement (BE)

\begin{tabular}{ll}
\hline Item number & Statement for response (given five point scale indicating how often) \\
\hline $21 \mathrm{p}$ & I really make an effort in my mathematics lessons \\
$22 \mathrm{p}$ & I concentrate hard in mathematics \\
$23 \mathrm{p}$ & I try to answer questions the teacher asks \\
$24 \mathrm{p}$ & If I make mistakes, I work until I have corrected them \\
$25 \mathrm{p}$ & If I can't do a problem, I keep trying different ideas \\
$26 \mathrm{p}$ & I test my understanding by doing exercises and problems \\
$27 \mathrm{p}$ & In mathematics I try to link new ideas to knowledge I already have \\
\hline
\end{tabular}


cepts canvassed in the questionnaire simple, leaving deeper exploration to other data collection devices. Our choices of items related to engagement were also informed by interviews with 10 teachers who are involved with the project. We asked these teachers what they would see as evidence of increased student engagement with mathematics. Their responses were dominated by behavioural features similar in nature to the items shown. For the items listed in Table 5 we ask students to reflect on how frequently they behave in various ways in their mathematics classes.

\section{Compiling the scale}

As indicated by Tables $1-5$ above, the trial instrument consisted of 27 items. It was planned around five subscales: mathematical confidence [MC], confidence with technology [TC], attitude to learning mathematics with technology (whether computers, graphics calculators or computer algebra systems) [MT], affective engagement [AE] and behavioural engagement [BE]. A Likerttype scoring format was used for each of the subscales: MC, TC, MT and AE. Students were asked to indicate the extent of their agreement with each statement, on a five-point scale from strongly agree to strongly disagree (scored from 5 to 1 ). A different but similar response set was used for the BE subscale. Students were asked to indicate the frequency of occurrence of different behaviours. A five-point system was again used - nearly always, usually, about half of the time, occasionally, hardly ever (scored again from 5 to 1 ). The content validity and face validity of the scale are assured by the development process, with all three authors debating the suitability of items, many of which were derived from previously published scales. A test-retest study of reliability has not been carried out.

\section{Evaluating the scale}

271 This scale was trialled with 350 students from 17 intact classes in grades $8-10$ at 6 secondary schools. These schools are typical of the range of secondary schools in Victoria (Australia) and include two private co-educational schools, two state co-educational schools and one girls' private school and one girls' state school. The schools vary from upper middle to low socio-economic status. For this trial we were not concerned with the unit of work being studied or to explore the hypothesized model of links between the variables in Fig. 1, merely to check the ease of administration and to examine the psychometric properties of the subscales. Administration proved simple, with few queries from teachers or their students, who completed it within 10-15 min.

\subsection{Factor structure and reliability of the preliminary and MTAS scale}

280 The items for the scale were constructed with five factors in mind, as indicated above. Factor analysis of the preliminary scale confirmed the five-factor structure, with all but a few items (discussed below) contributing as planned to the scale. However, the factor and reliability analysis, together with examination of inter-item correlations, further suggested that the scale could be simplified to five factors with four items per factor. This modification results in a scale which is both quick and very easy to use. We call the selected item set Mathematical and Technology Attitudes 
Scale (MTAS) and it is included as Appendix A. Users of the MTAS can easily obtain each subscale score by adding the responses to the four items. Students can complete it within $10 \mathrm{~min}$.

After the initial factor analysis and reliability analysis, seven items were deleted from the set. Omitting items $4 \mathrm{p}, 18 \mathrm{p}$ and $21 \mathrm{p}$ from the TC, MC and BE sets led to increased Cronbach's alpha in the respective subscales. In the MT subset, item 9p correlated highly with items 4p, 8p, 15p and $20 \mathrm{p}$ and was therefore redundant and hence could be omitted. In the initial factor analysis, item $13 \mathrm{p}$ ("Mathematics is boring") linked more closely with MC than with its intended AE. Item 13p was also the only negatively worded item and as such was open to coding error by future users. It was therefore omitted. While there was no strong positive or negative statistical consequence of the choice of the two further items to delete from the BE subset, items $26 \mathrm{p}$ and $27 \mathrm{p}$ focus on deeper aspects of learning style and cognitive engagement than other items, and are therefore omitted. Factor analysis and reliability analysis were then re-applied to the resulting 20-item MTAS.

Statistical analysis using data from 350 complete students' responses to the 20 items forming the MTAS indicates that this data satisfies the underlying assumptions of Principal Components Analysis and that together five factors (each with eigenvalue greater than 1) explain $65 \%$ of the variance, with almost $26 \%$ attributed to the first factor, MC. Reliability analysis yields satisfactory Cronbach's alpha values for each subscale (MC, .87; MT, .89; TC, .79; BE, .72 and AE, .65). This indicates a strong or acceptable degree of internal consistency in each subscale.

\section{4}

\section{Using the MTAS to explore school and gender variation}

305 MTAS subscale scores can be calculated by simple addition of responses. With a maximum 306 possible score on any subscale of 20 and a minimum of 4 , we consider scores of 17 or above to be high, indicating a very positive attitude, $13-16$ to be moderately high and 12 or below to be a low score reflecting a neutral or negative attitude to that factor.

\section{9}

\subsection{Variation of MTAS scores amongst schools}

310 In this section we report on the responses of different schools on the MTAS variables (20 items only), again from the sample of 350 students. Fig. 2 gives the box plots for all subscales, and then, for each of the schools, on each MTAS subscore. The number of students responding at each school varies from 16 (School F) to 152 (School C) with an average of 59 students per school.

314 The boxplots for the school results show no obvious links between the five subscales. Scores on three of the subscales (affective engagement AE, behavioural engagement BE and confidence with technology TC) have similar medians at all schools, and students have generally high or moderately high scores. Whilst the high scores for the self-reported behavioural engagement might be expected, it is good to see that only in one school (E) did more than $25 \%$ of students score less than 12 in affective engagement (AE) (i.e., lower average than the neutral response), and in all of the schools at least $75 \%$ of students scored more than 12 on confidence with technology (TC). Given the uniform means on the first three subscales, it is interesting to observe the variation between schools in mathematics confidence (MC) and attitude to learning mathematics with technology (MT). 

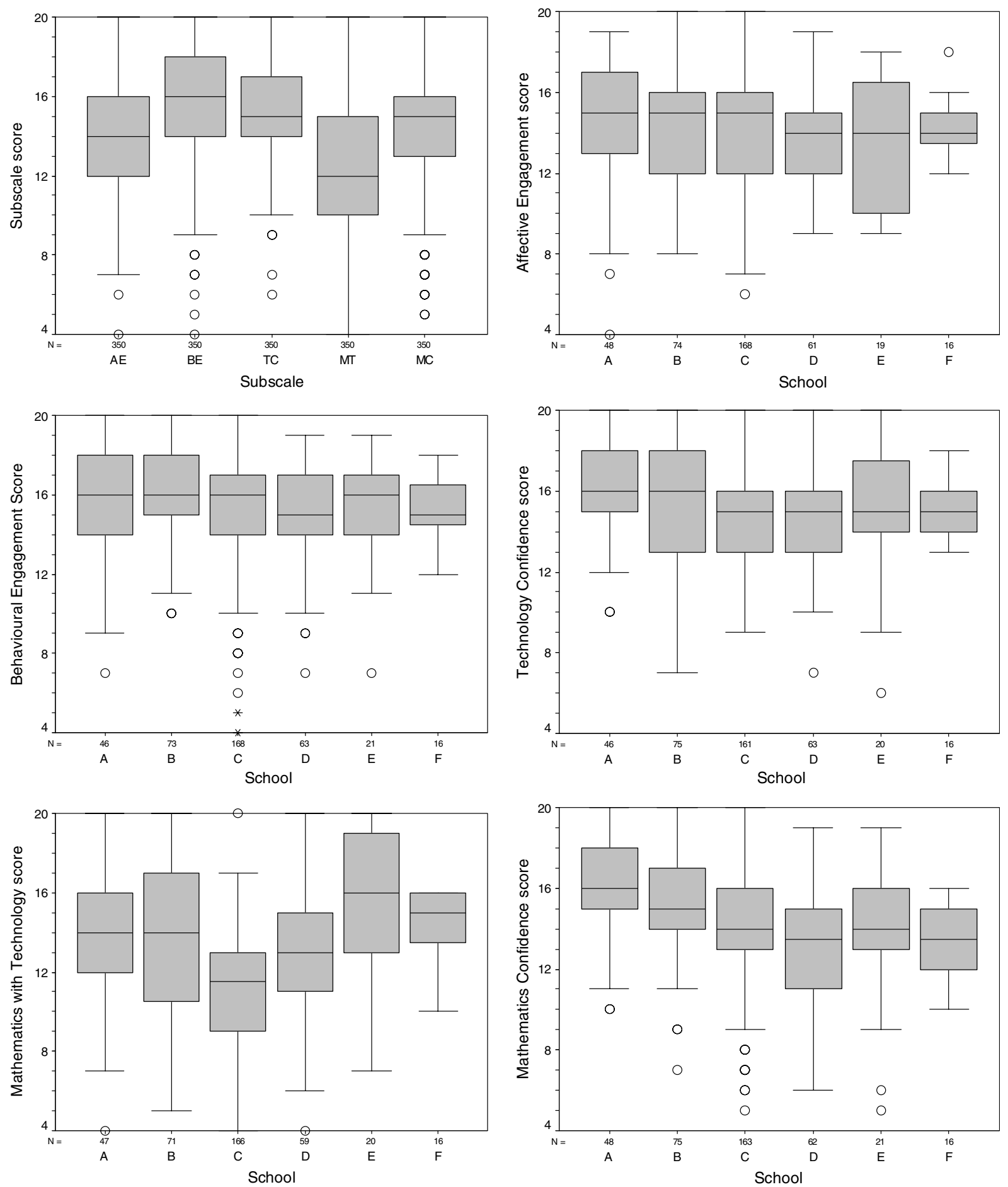

Fig. 2. Box plots showing distribution of MTAS subscale scores for 350 students and for each subscale by school. 
324 The scores on MT are the most interesting for this paper. At four schools, some students gave the maximum possible score. At two schools, some students gave the minimum possible score. Students' opinions on learning mathematics with technology are therefore divided, even within schools. We might discount the results from School C because at the time of the survey, these students had little experience of learning mathematics with technology. However, we cannot discount the results from School B, where technology use is well established in mathematics classes. At the time of the survey, School E had just finished their first experience of using graphics calculators in mathematics: this good experience may explain the high scores, although the long tail is also present once again indicating that there is considerable variability in students' evaluations of learning mathematics with technology. Some of this variability may be due to consistent differences between boys and girls. For example, in their study of a small sample of students of a similar age and similar location to the present study, Vale and Leder (2004) found that boys view computer-based mathematics lessons more favourably than girls. Gender differences are therefore examined in the next section.

\subsection{Gender differences}

39 Gender differences in attitudes to mathematics have long been of interest (Fennema \& Sherman (1976) is an early study), and a question of current interest is whether using technology to learn mathematics exacerbates differences. This section therefore reports results on the five subscales by gender. In order to remove between-school influences from the data, only the responses from the four coeducational schools are considered in this section. This means that the boys and girls in the sample have experienced the same learning environments. One hundred and forty-one ( 70 boys and 71 girls) completed all items although more students ( 152 total) completed all items of some subscales.

The breakdown of these scores by gender, illustrated in Fig. 3, reveals that boys have statistically significantly higher scores than girls for each subscale except BE $(t=-.005, d f=151$, $p=.996)$. The differences are greatest for TC $(t=6.84, d f=152, p=.000)$ and $\mathrm{MC}(t=6.13$, $d f=155, p=.000)$ with MT $(t=2.85, d f=149, p=.005)$ and $\mathrm{AE}(t=2.56, d f=152, p=.011)$ demonstrating less difference. While $50 \%$ of boys score $16+$ on MC, this was true for only $25 \%$ of girls. TC scores are even more strongly higher for boys, with approximately $75 \%$ of boys scoring $16+$ and only $25 \%$ of the girls. These results reflect the common finding that boys express greater confidence than girls, but they contrast with those of Vale and Leder (2004) who found gender differences only on their variable corresponding to MT. It is important to note that not all the students with negative attitudes to learning mathematics with technology are girls. The distributions of MT have a long tail for both boys and girls and high inter-quartile ranges (the highest for the boys' scores). The high variability in MT is therefore not explained by gender differences: we need to look beyond learning environment and gender to explain the range of students' evaluations of the effectiveness of learning with technology.

360 Table 6 presents the correlations between the subscale scores for the 141 students from the co-ed schools, and also for males and females separately. There are statistically significant positive correlations (weak or moderate) between all pairs of AE, BE, MC and TC. The correlations between AE, $\mathrm{BE}$ and $\mathrm{MC}$ may be explained by their common concern with school mathematics. The correlations with TC are perhaps surprising, but may possibly be explained by a home background factor, linking inclination to school mathematics with technical interests and equipment in the home. 


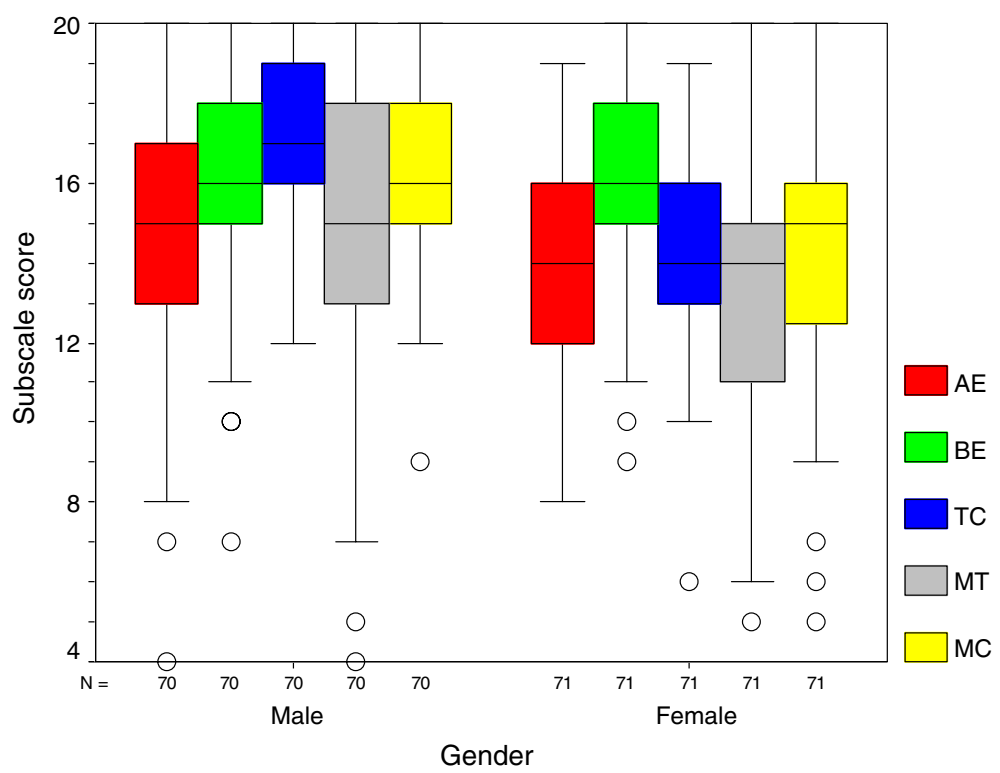

Fig. 3. MTAS scores for subscales by gender.

Table 6

Correlations for males and females between MTAS subscale scores

\begin{tabular}{llllll}
\hline & & BE & TC & MT & MC \\
\hline AE & Combined & $.471^{* *}$ & $.308^{* *}$ & .021 & $.549^{* *}$ \\
& Male & $.307^{* *}$ & $.266^{* *}$ & .171 & $.605^{* *}$ \\
& Female & $.506^{* *}$ & $.284^{* *}$ & -.082 & $.529^{* *}$ \\
BE & & $.240^{* *}$ & .012 & $.452^{* *}$ \\
& Combined & 1 & $.289^{*}$ & .131 & $.271^{*}$ \\
& Male & & $.217^{* *}$ & -.047 & $.492^{* *}$ \\
TC & Female & & $.240^{* *}$ & $.509^{* *}$ \\
& Combined & & & $.358^{* *}$ & $.489^{* *}$ \\
& Male & & & .064 & $.427^{* *}$ \\
MT & Female & & & & -.033 \\
& Combined & & & & .116 \\
& Male & & & & $-.223^{* *}$ \\
& Female & & & & \\
\end{tabular}

${ }^{*}$ Correlation is significant at the .05 level ( 2 tailed).

** Correlation is significant at the .01 level ( 2 tailed).

366 The variable MT is, with two exceptions, not significantly correlated with the others. However, it is correlated positively with TC for boys and negatively with MC for girls. The positive correlation for boys is consistent with the findings of Vale and Leder (2004), although as noted above, their measure of "computing achievement" is somewhat different. The significant negative correlation for girls with mathematics confidence is in the opposite direction to the 
371

372

373

374

375

376

377

378

379

380

381

382

383

384

385

386

387

388

390

391

393

394

395

\section{6}

\section{Conclusion}

397 This paper outlines the rationale for, construction, analysis and application of a simple scale for 398

(non-significant) correlation found in the Vale and Leder study. We have two explanations for its negative direction. It may be that there is a weak tendency for those girls whose confidence is based on their self-perception that they can learn to follow rules diligently, not to value technology for learning mathematics because it may take over from them this same accurate performance of routine procedures. An alternative explanation is that there is a weak tendency for girls who do not feel confident about mathematics to value using technology for learning mathematics more. Both of these situations have been reported in case study data by Pierce and Stacey (2004). The data available does not provide conclusive evidence to decide which, if either, of the two explanations applies more frequently and hence might cause the negative correlation. However, examination of the scattergram for MT and MC for girls demonstrates that group of the lowest confidence girls generally value technology for learning, lending support to the second explanation. However the scattergram also shows that the most confident group of girls exhibit a range of valuing of technology, which may be due to different reactions from girls whose high confidence is differently based; which is consistent with the first explanation. These explanations therefore warrant further investigation. Whereas boys may experience learning mathematics more positively simply because technology is present, some girls may value it when they feel it has the potential to compensate for self-perceived shortcomings.

In interpreting all the gender differences, it is important to note that only a few girls actually expressed negative responses (total score less than 12) to any of the factors. It is not that the girls' scores are very low, rather that there was a more highly positive response from the boys.

392 In every school, most students agreed rather than disagreed that it was better to learn mathematics with technology. These results suggest that this scale is proving to be suitable for discriminating differences between cohorts of students and hopefully for indicating change over time with repeated administration. assessing students' attitudes to mathematics, technology and the learning of mathematics with technology. The Mathematics and Technology Attitudes Scale (MTAS) questionnaire consists of only 20 short items and can be administered in less than $10 \mathrm{~min}$. The analysis is simple, since the scores on the items are simply added to get the subscale scores. Modification of the last four items tailors the scale for students who regularly use computers, graphics calculators or other mathematical analysis tools. If desired, the MT items can be repeated in different versions to measure attitudes to learning with another technology. They are placed last on the scale to make this easier.

405 Administering the scale to students in 6 schools provided information about differences between schools and genders, and also gave some clues as to what variables contribute and do not contribute to students' evaluation of the effectiveness of learning mathematics with technology. As we work through the potential opportunities offered by technology for enhancing the teaching and learning of mathematics it is important that all aspects are monitored. This scale provides an instrument that can be used in classrooms by either teachers or researchers interested in trialling teaching innovations which include the use of new technology. 


\section{Acknowledgements}

413 The authors thank the teachers and students of the RITEMATHS project for generously giving 414 their time to supply data for this study. The project is funded by the Australian Research Council, 415 with Chief Investigators Kaye Stacey, Gloria Stillman and Robyn Pierce.

\section{Appendix A. Mathematics and Technology Attitudes Scale}

417 (Final version showing the usually invisible subscale membership of items)

418 FIVE SUBSCALES: mathematics confidence [MC], confidence with technology [TC], attitude 419 to learning mathematics with technology [MT], affective engagement [AE] and behavioural 420 engagement [BE]. To tailor MT items to a particular class, change the words "graphics calculators" to the technology used by that class (e.g., computers, graphics calculators, computer algebra systems). Do not change TC items.

\begin{tabular}{|c|c|c|c|c|c|c|}
\hline & & $\begin{array}{l}\text { Hardly } \\
\text { Ever }\end{array}$ & Occasionally & $\begin{array}{l}\text { About Half } \\
\text { the time }\end{array}$ & Usually & $\begin{array}{l}\text { Nearly } \\
\text { Always }\end{array}$ \\
\hline 1. & I concentrate hard in mathematics $[\mathrm{BE}]$ & $\mathrm{HE}$ & $\mathrm{Oc}$ & $\mathrm{Ha}$ & $\mathrm{U}$ & NA \\
\hline 2. & $\begin{array}{l}\text { I try to answer questions the teacher asks } \\
\text { [BE] }\end{array}$ & $\mathrm{HE}$ & Oc & $\mathrm{Ha}$ & $\mathrm{U}$ & NA \\
\hline 3. & $\begin{array}{l}\text { If I make mistakes, I work until I have } \\
\text { corrected them. }[\mathrm{BE}]\end{array}$ & $\mathrm{HE}$ & Oc & $\mathrm{Ha}$ & $\mathrm{U}$ & NA \\
\hline \multirow[t]{2}{*}{4.} & $\begin{array}{l}\text { If I can’t do a problem, I keep trying } \\
\text { different ideas. [BE] }\end{array}$ & $\mathrm{HE}$ & Oc & $\mathrm{Ha}$ & $\mathrm{U}$ & NA \\
\hline & & $\begin{array}{l}\text { Strongly } \\
\text { disagree }\end{array}$ & Disagree & Not sure & Agree & $\begin{array}{l}\text { Strongly } \\
\text { agree }\end{array}$ \\
\hline 5. & I am good at using computers $[\mathrm{TC}]$ & $\mathrm{SD}$ & $\mathrm{D}$ & NS & A & SA \\
\hline 6. & $\begin{array}{l}\text { I am good at using things like VCRs, } \\
\text { DVDs, MP3s and mobile phones [TC] }\end{array}$ & SD & $\mathrm{D}$ & NS & A & SA \\
\hline 7. & I can fix a lot of computer problems [TC] & SD & $\mathrm{D}$ & NS & A & SA \\
\hline 8. & $\begin{array}{l}\text { I am quick to learn new computer } \\
\text { software needed for school [TC] }\end{array}$ & SD & $\mathrm{D}$ & NS & A & SA \\
\hline 9. & I have a mathematical mind [MC] & SD & $\mathrm{D}$ & NS & A & SA \\
\hline 10. & $\begin{array}{l}\text { I can get good results in mathematics } \\
{[\mathrm{MC}]}\end{array}$ & $\mathrm{SD}$ & $\mathrm{D}$ & NS & A & SA \\
\hline 11. & $\begin{array}{l}\text { I know I can handle difficulties in } \\
\text { mathematics [MC] }\end{array}$ & SD & $\mathrm{D}$ & NS & A & SA \\
\hline 12. & I am confident with mathematics [MC] & SD & $\mathrm{D}$ & NS & A & SA \\
\hline 13. & $\begin{array}{l}\text { I am interested to learn new things in } \\
\text { mathematics }[\mathrm{AE}]\end{array}$ & SD & $\mathrm{D}$ & NS & A & SA \\
\hline 14. & $\begin{array}{l}\text { In mathematics you get rewards for your } \\
\text { effort }[\mathrm{AE}]\end{array}$ & SD & $\mathrm{D}$ & NS & A & SA \\
\hline 15. & Learning mathematics is enjoyable $[\mathrm{AE}]$ & SD & $\mathrm{D}$ & NS & A & SA \\
\hline 16. & $\begin{array}{l}\text { I get a sense of satisfaction when I solve } \\
\text { mathematics problems }[\mathrm{AE}]\end{array}$ & SD & $\mathrm{D}$ & NS & A & SA \\
\hline
\end{tabular}


Appendix A (continued)

\begin{tabular}{|c|c|c|c|c|c|c|}
\hline & & $\begin{array}{l}\text { Hardly } \\
\text { Ever }\end{array}$ & Occasionally & $\begin{array}{l}\text { About Half } \\
\text { the time }\end{array}$ & Usually & $\begin{array}{l}\text { Nearly } \\
\text { Always }\end{array}$ \\
\hline 17. & $\begin{array}{l}\text { I like using graphics calculators for } \\
\text { mathematics }[\mathrm{MTg}]\end{array}$ & SD & $\mathrm{D}$ & NS & A & SA \\
\hline 18. & $\begin{array}{l}\text { Using graphics calculators in } \\
\text { mathematics is worth the extra effort } \\
\text { [MTg] }\end{array}$ & SD & $\mathrm{D}$ & NS & A & SA \\
\hline 19. & $\begin{array}{l}\text { Mathematics is more interesting when } \\
\text { using graphics calculators. [MTg] }\end{array}$ & SD & $\mathrm{D}$ & NS & A & SA \\
\hline 20. & $\begin{array}{l}\text { Graphics calculators help me learn } \\
\text { mathematics better [MTg] }\end{array}$ & SD & $\mathrm{D}$ & NS & A & SA \\
\hline
\end{tabular}

\section{References}

425

Chapman, E. (2003). Development and validation of a brief mathematics attitude scale for primary-aged students. Journal of Educational Enquiry, 4(2), 63-73.

Fennema, E., \& Sherman, J. (1976). Fennema-Sherman Mathematics Attitudes Scales. Instruments designed to measure attitudes toward the learning of mathematics by females and males. Abstracted in the JSAS Catalog of Selected Documents in Psychology, 6(1), 31 (Ms No. 1225).

Fogarty, G., Cretchley, P., Harman, C., Ellerton, N., \& Konki, N. (2001). Validation of a questionnaire to measure mathematics confidence, computer confidence, and attitudes towards the use of technology for learning mathematics. Mathematics Education Research Journal., 13, 154-160.

Forgasz, H. (1995). Gender and the relationship between affective beliefs and perceptions in grade 7 mathematics classroom learning environments. Educational Studies in Mathematics, 28, 219-239.

Fredricks, J., Blumenfeld, P., \& Paris, A. (2004). School engagement: potential of the concept, state of the evidence. Review of Educational Research, 74(1), 59-109.

Galbraith, P., \& Haines, C. (1998). Disentangling the nexus: attitudes to mathematics and technology in a computer learning environment. Educational Studies in Mathematics, 36, 275-290.

HREF1 RITEMATHS project. (2004). Available from: www.extranet.edfac.unimelb.edu.au/DSME/RITEMATHS. University of Melbourne. Accessed 26 November.

Mayes, R. (1998). ACT in algebra: student attitude and belief. International Journal of Computer Algebra in Mathematics Education, 5(1), 3-13.

McLeod, D. B. (1992). Research on affect in mathematics education: a reconceptualisation. In D. A. Grouws (Ed.), Handbook of research on mathematics teaching and learning (pp. 575-596). New York: MacMillan.

Oldknow, A. (2003). Mathematics from still and video images. Micromath. Summer, 2003, 30-34.

Pajares, M. F. (1992). Teachers' beliefs and educational research: cleaning up a messy construct. Review of Educational Research, 62(3), 307-322.

Pierce, R., \& Stacey, K. (2004). A framework for monitoring progress and planning teaching toward the effective use of computer algebra systems. International Journal of Computers for Mathematical Learning., 9(1), 59-93.

Ruffell, M., Mason, J., \& Allen, B. (1998). Studying attitude in mathematics. Educational Studies in Mathematics, 35, $1-18$.

Tapia, M., \& Marsh II, G. (2004). An instrument to measure mathematics attitudes. Academic Exchange Quarterly, $8(2), 1-8$.

Vale, C., \& Leder, G. (2004). Student views of computer-based mathematics in the middle years: does gender make a difference?. Educational Studies in Mathematics, 56, 287-312. 